\title{
Crossing borders: key features of migrant social workers in New Zealand
}

\author{
A. Bartley, L. Beddoe, J. Duke, C. Fouché, P. Harington and R. Shah
}

Dr Allen Bartley is a Senior Lecturer at the School of Counselling, Human Services and Social Work, Faculty of Education University of Auckland. Associate Professor Liz Beddoe works at the School of Counselling, Human Services and Social Work, Faculty of Education, University of Auckland. Dr Jan Duke is the Deputy Registrar of the Social Workers Registration Board. Associate Professor Christa Fouche works at the School of Counselling, Human Services and Social Work, Faculty of Education, University of Auckland. Phil Harington is the Principal Lecturer and the Head of School of Counselling, Human Services and Social Work, Faculty of Education, University of Auckland. Ritesh Shah is a doctoral student at the School of Critical Studies in Education, Faculty of Education, University of Auckland.

\begin{abstract}
The emergence of a mobile, professional social work workforce, successfully managing the demands of service-users, policy makers and the public at large in different countries across the globe, provides unprecedented opportunities for professional border-crossing. It is timely to generate New Zealand-specific data on professionals employed in the social services workforce in New Zealand so as to inform educational and institutional responses to this complex phenomenon. A study that seeks to develop a profile of migrant social workers in New Zealand and key issues experienced by these professionals, is underway. This article reports on the first phase of the project, comprising an examination of the key features of registered social workers in New Zealand with an overseas social work qualification and a review of issues and challenges faced by migrant professionals more generally, and by migrant social workers in particular.
\end{abstract}

\section{Introduction}

Since its beginnings in the last third of the 19th century, social work has become a global profession practised in over 144 countries according to the International Association of Schools of Social Work (IASSW). Its spread and development have been accompanied by a drive to attain professional status and a coherent international identity through the work of a number of international organisations concerned with social work practice and education, such as the International Federation of Social Workers (IFSW) and the IASSW. Workforce mobility and professional registration are two significant issues impacting on the social work profession, both in New Zealand, which is a focus of this article, and in the international context. Over the past decade social work has steadily moved towards greater regulation and New Zealand, the United Kingdom, Ireland and South Africa have national registration arrangements. Licensing is regulated within the various jurisdictions of the United States 
and Canada. The IASSW Global Qualifying Standards document (IASSW, 2005) recognises the increasing mobility of the profession and aims for consistency within and between qualifications to facilitate portability. A major consequence of regulation is that, having regulated qualifications and standards for social work, regulatory bodies need to reconcile their standards with the need to recruit those with overseas qualifications, particularly where shortages of graduates may lead to offshore recruitment strategies.

The second significant issue, and another focus of this article, is the increasing number of social workers participating in a more international labour market, subject to push-pull factors (Lyons, 2006). Professional bodies' responses to this are being driven by a range of governmental arrangements and international agreements (Beddoe \& Duke, 2009). One such agreement of particular relevance for social work in New Zealand is the Trans-Tasman Mutual Recognition Act (1997), which provides for an arrangement between the Australian Commonwealth, State and Territory governments and the Government of New Zealand. This arrangement implements mutual recognition principles relating to the sale of goods and the registration of occupations, including the principle that 'a person registered to practise an occupation in Australia is entitled to practise an equivalent occupation in New Zealand, and vice versa, without the need for further testing or examination' (Department of Innovation, Industry, Science and Research, 2009). Increasingly, mutual recognition agreements are governing the movement of workers, including social workers, in other jurisdictions. The North American Free Trade Agreement facilitates movement of social workers between the USA and Canada (White, 2006) and the European Union has similar arrangements.

Data from the 2006 Census suggest $22.9 \%$ of people usually living in New Zealand (or 879,543 people) were born overseas, with an estimated $37 \%$ of people in the greater Auckland region being overseas born (Statistics New Zealand). The net migration figure of 56,100 people in the five years 2003 to 2008 does not adequately reflect the significant movement of people across our borders, with 411,400 arrivals and 355,300 departures during this time. This movement of people between countries includes potential/actual social work service users, social work practitioners and social work educators. It is becoming increasingly clear that professional discourses, practices and education defined and operationalised within the confines of one country are no longer sufficient to deal with the movement of people and ideas across borders. New forms of global social work practice and internationalisation of education are emerging in response to these new mobilities, and it is inevitable that new forms of social work education and training need to be considered to take account of the increasing complexities that have been created by intensification in border crossings. However, there is a paucity of knowledge on these complexities, and in particular the profile of and issues experienced by professionals employed in the social services workforce, including:

- migrant professionals, trained in a country other than the country where they are employed,

- returning migrant professionals, who have worked extensively internationally and remigrate to the country where they have originally been trained (some of these returning to New Zealand and others working in New Zealand with the aim to return to their home country),

- transnational professionals, who are anchored in one place, based either in their country of origin or any other country, but with professional and collegial relationships that 
transcend national boundaries and involve multidirectional and routine 'flows' of information,

- returning transnationals, locally born, who have gained overseas training and employment experience, and then return to fill professional roles in their home country (and who may also be considered 'migrant social workers'), and

- native-born professionals, who are trained and employed in their home country, and work alongside colleagues from any of the above groups.

Of the 2,485 registered social workers in New Zealand (as at May 21, 2010), approximately 9\% were registered with an initial overseas qualification. Members of the 'Workforce Dynamics Research Programme' in the School of Counselling, Human Services and Social Work, at the University of Auckland, have increasingly become aware of the diverse profile of practitioners educated and employed in the social services sector in New Zealand and the challenges of providing ongoing professional development to meet the diverse demands of this sector. In addition, the research developments internationally have been noted and this research team aims to generate New Zealand-specific data on professionals employed in the social services workforce in New Zealand.

This article reports on the first phase of a larger study, 'Crossing Borders: An exploration of migrant professional workforce dynamics'. It comprises an examination of key features of the 234 people currently registered as social workers in New Zealand (as at May, 2010) who hold a social work qualification gained in a country other than New Zealand, as well as issues and challenges faced by migrant social workers and other migrant professionals more generally. Focus group interviews with key migrant social work practitioners have been carried out and a survey of migrant social workers in New Zealand is underway at the time of writing. The key research questions for this study are: what is the profile of the migrant social work workforce in New Zealand and what are the key professional issues experienced by this specific cohort of the migrant workforce?

\section{Background}

A literature review was conducted by searching social science databases (Web of Science, Social Work Abstracts, Social Sciences Citation Index, Social Care Online, ProQuest, etc.), covering most of the field's English-language academic journals, utilising keywords such as 'social work', 'migration', 'crossing borders', 'immigration' and 'globalisation'. More than 250 journal articles, books, professional association newsletter articles, policy documents and web pages resulted. The abstracts or introductions to all of these documents were reviewed, and from that approximately 50 were deemed as relevant or important for the purposes of this review. It is noted that there was a visible absence of academic literature related to the experiences of migrant social workers in New Zealand. A discussion on issues and challenges faced by these professionals will follow later in this article, but a range of material on skilled migrants in general provides a significant background to these discussions.

Since 1987, immigration policies within the Department of Labour have aimed to encourage the settlement of skilled or highly skilled migrants to New Zealand, and since 2003 such policies have particularly focused on professions facing chronic labour short- 
ages (Masgoret, Merwood \& Tausi, 2009). The skilled migrant scheme is a points-based policy that allows individuals and their families to gain permanent residence if they have the skills, qualifications and professional experience to contribute economically and socially to New Zealand. This scheme allocates points to individuals for their highest level of education, years of professional experience, attainment of English proficiency (for those coming from a non-English-speaking country), proof of an existing job or job offer in New Zealand, and whether their profession is one specified on the Department of Labour's 'Essential Skill Shortage List'. As of early 2010, migrants who score at least 100 points are encouraged to complete an Expression of Interest (EOI), from which they may or may not be selected to lodge a full application for residency (New Zealand Immigration Service, 2009).

According to the latest data on migrants to New Zealand, more than $50 \%$ of those entering the country from July 2008 to July 2009 arrived under the skilled migrant category (IMSED Research, 2009). During this period, the largest numbers of skilled migrants arrived from the United Kingdom (20\%), South Africa (19\%), the Philippines (11\%), China (10\%) and Fiji (8\%). Most skilled migrants arriving in New Zealand are aged between 25 and 44, as preference is given under the current scheme to younger applicants.

While skilled migrants receive points in the immigration scheme for qualifications and professional experience - weighted if these align with domestic skills shortages - such considerations do not necessarily coincide with actual employment outcomes. Research, both in New Zealand and internationally, suggests that resettlement, and in particular gaining employment, is not as easy for migrant health care professionals as it is for other groups of skilled migrants crossing borders. A significant issue for many health care professionals is the difficulty they face in getting registered for practice in their new country of settlement. For example, overseas trained doctors migrating to New Zealand cite attaining registration as one of the more difficult aspects of their resettlement - contending that the process is difficult, expensive, confusing and often time-consuming (Lillis, St George, \& Upsdell, 2006). Gaining equivalency and recognition for qualifications and registration certificates obtained overseas is often the issue that impedes health care professionals from attaining full registration to practice in New Zealand (North, Trlin, \& Singh, 1999; Lillis et al., 2006). While doctors initially denied full equivalency are given the option to undergo a prescribed course of study and ongoing supervision to 'fill the gaps', the time and/or cost involved precludes some doctors from doing so. This has led many to not practise within their discipline, to engage a transnational strategy to return to practise in their country of origin while their families remain in New Zealand (Bartley \& Spoonley, 2008), or to abandon the profession altogether.

\section{Key features of migrant social workers in New Zealand}

In 2005, the Department of Labour published a report looking specifically at the present and future labour market situation for social work in New Zealand (cited in SWRB, 2007b, p.17). The report concluded that growth in the supply of social workers has not kept up with demand, as a result of an aging population and increased government expenditure on care, protection and mental health services. It was also noted that sufficient numbers of future social workers could not be produced within the New Zealand labour market, as the number of students choosing to study social work was too low, and the profession suffered from high attrition rates of New Zealand-trained professionals. The conclusion of this analysis 
was that shortfalls in the social work workforce were to continue into the foreseeable future, and that it would be necessary to encourage foreign social workers to migrate to New Zealand and practise within their discipline to meet this labour shortage. As a result, social work is currently listed on the Long Term Skills Shortage List, allowing migrants with a social work background to apply for either a work to residence or residency permit in New Zealand (New Zealand Immigration Service, 2010). Migrants with a degree equivalent to a New Zealand Bachelor in Social Work or a postgraduate qualification in social work (as assessed by the New Zealand Qualifications Authority) are able to claim points as a social work professional on their application.

Similar to other countries, such as England and Australia, New Zealand has been actively recruiting social workers from abroad to fill a critical labour shortage that cannot be met internally. The literature from the United Kingdom and Ireland suggests that social work agencies aggressively recruit and market to migrants the benefits of moving to the country, in the hope that this labour pool will fill gaps in its social care system (Penna, Paylor, \& Washington, 2000; White, 2006; Welbourne, Harrison, \& Ford, 2007; van Lanen, 2008; Christie \& Campbell, 2009; Simpson, 2009; Walsh, Wilson, \& O'Connor, 2010). There are signs that this aggressive campaign has had success. In the United Kingdom, between 2003 and 2004 there was an 82 percent increase in the number of overseas-qualified social workers entering the country, with the greatest numbers coming from Australia, South Africa and the USA (Welbourne et al., 2007, p.29). In London and the South East, where labour shortages within the profession are most acute, migrant social workers make up almost half the workforce (Simpson, 2009). With the heavy recruitment of migrant social workers across all these systems, increasing attention is being paid in the literature to the experiences of social workers crossing borders, and the perspectives of the colleagues, clients and employers they work with and for.

The existing literature and data collected on those practising social work in New Zealand provides a limited perspective on the demographic nature of those immigrating to the country and continuing their profession. As noted above, approximately $9 \%$ of registered social workers (a small proportion of practising social workers) in New Zealand hold an initial foreign qualification. As a particular cohort of skilled migrants, border-crossing social workers must confront the same challenges posed to skilled migrants more generally. However, the nature of the profession and the work done by social workers create in their migration experience additional dynamics of complexity. Analysis of cohort data from the New Zealand Social Work Registration Board (SWRB) allows us to illustrate in finer detail the distinct manifestations of the issues faced by migrant social workers in New Zealand, and to identify patterns in the ways that individual migrant social workers, as well as agencies which employ them, respond to them.

The overseas-qualified social workers practising in New Zealand and registered with the SWRB are drawn from virtually every region of the world (Table one) - including 23 born in New Zealand and trained elsewhere. A third of the migrant social workers registered with the SWRB are from the UK and Ireland, with a further $18 \%$ from elsewhere in Europe. The numbers coming from North America are similar to those from South Asia (18 from the USA and Canada; 19 from India and Bangladesh). Only nine were born in East Asia, and only one in the Middle East. Of the 35 registered social workers originally from the African continent, 34 were born in South Africa. 
Table one. Country of birth.

\begin{tabular}{|c|c|c|c|c|c|}
\hline Country & $\mathbf{N}$ & $\%$ & Region & $\mathbf{N}$ & $\%$ \\
\hline England & 63 & 26.9 & & & \\
\hline Scotland & 7 & 3 & & & \\
\hline Wales & 4 & 1.7 & & & \\
\hline Ireland & 2 & 0.9 & & & \\
\hline Northern Ireland & 2 & 0.9 & UK \& Ireland & 78 & 33.3 \\
\hline Austria & 1 & 0.4 & & & \\
\hline Belgium & 1 & 0.4 & & & \\
\hline Bulgaria & 1 & 0.4 & & & \\
\hline Czech Republic & 1 & 0.4 & & & \\
\hline France & 2 & 0.9 & & & \\
\hline Germany & 16 & 6.8 & & & \\
\hline Italy & 1 & 0.4 & & & \\
\hline Malta & 1 & 0.4 & & & \\
\hline Monaco & 1 & 0.4 & & & \\
\hline Netherlands & 13 & 5.6 & & & \\
\hline Romania & 2 & 0.9 & & & \\
\hline Switzerland & 1 & 0.4 & & & \\
\hline Yugoslavia & 1 & 0.4 & Europe & 42 & 17.9 \\
\hline South Africa & 34 & 14.5 & & & \\
\hline Zambia & 1 & 0.4 & Africa & 35 & 15.0 \\
\hline Australia & 8 & 3.4 & & & \\
\hline Fiji & 1 & 0.4 & & & \\
\hline NZ & 23 & 9.8 & Oceania & 32 & 13.7 \\
\hline India & 17 & 7.3 & & & \\
\hline Bangladesh & 2 & 0.9 & South Asia & 19 & 8.1 \\
\hline Canada & 8 & 3.4 & & & \\
\hline USA & 10 & 4.3 & North America & 18 & 7.7 \\
\hline Hong Kong & 2 & 0.9 & & & \\
\hline Korea & 1 & 0.4 & & & \\
\hline Philippines & 5 & 2.1 & & & \\
\hline Singapore & 1 & 0.4 & East Asia & 9 & 3.8 \\
\hline Lebanon & 1 & 0.4 & West Asia/Middle East & 1 & 0.4 \\
\hline Total & 234 & 100 & Total & 234 & 100 \\
\hline
\end{tabular}

Approximately $13 \%$ of all skilled migrants entering the country end up working in health or health-related professions, the category under which social work as a profession is classified, according to the Department of Labour. Seventy percent of skilled migrants arrive with several years of professional experience in their field overseas, with more than $50 \%$ of the group having worked in their discipline for over 10 years (Masgoret et al., 2009). 
The SWRB data illustrate clearly the prominence of the health sector for those migrant social workers who have obtained registration in New Zealand, as more than $40 \%$ of the overseas-qualified social workers were employed by a District Health Board at the time of their application for registration. A further third were employed in the Department of Child, Youth and Family Services. Most of the remaining applicants were working in the NGO sector, spread across agencies providing health and mental health services, child and family services and advocacy. Several were working in Māori organisations or in tertiary education (Table two). The time since earning their registerable qualifications ranged between three and 43 years ago, although the average time since earning their qualification was 17 years ago, suggesting that they come to New Zealand with significant professional experience. The average age of the cohort is 46 years.

Table two. Employer at time of application.

\begin{tabular}{lll}
\hline & N & $\%$ \\
DHB & 98 & 41.9 \\
CYFS & 78 & 33.3 \\
Child/Family Welfare \& Support Services (NGO) & 18 & 7.7 \\
Tertiary Education & 8 & 3.4 \\
Community Health/Mental Health Organisations (NGO) & 6 & 2.6 \\
Services for People with Impairments (NGO) & 8 & 3.4 \\
Māori Organisations & 4 & 1.7 \\
Counselling/Drug Rehabilitation & 3 & 1.3 \\
SWRB & 2 & 0.9 \\
Primary/Secondary School & 1 & 0.4 \\
Department of Corrections & 1 & 0.4 \\
Self-employed & 1 & 0.4 \\
Services for Refugees (NGO) & 1 & 0.4 \\
Methodist Mission & 1 & 0.4 \\
Misc. Community Services & 4 & 1.7 \\
Total & & \\
& 234 & 100.0 \\
\hline
\end{tabular}

However, given that registration is not mandatory and is required only for some social work positions, and only in some sectors, many people may be employed in a range of roles and may practise social work, while not actually being registered. As a result, the number of overseas-qualified social workers who are registered is likely to be only a sub-set of the numbers of the migrant 'social workers' working in New Zealand. Nash and Trlin's (2004, p.34) demographic analysis would suggest that the actual numbers of foreign-born individuals practicing social work or social work-related duties may be much higher. Consequently, it is instructive to explore the processes involved in obtaining New Zealand registration, and the reasons why professionals - who may well hold professional registration in other jurisdictions - may choose to delay, or even forego altogether, seeking registration in New Zealand. Given the non-mandatory status of registration, the most prominent issue for those overseas-qualified professionals who do pursue New Zealand registration is around the recognition and harmonisation of educational qualifications. 


\section{Qualifications}

Overseas-qualified social workers must have their qualifications compared to an equivalent New Zealand-based qualification (Social Workers Registration Act 2003, Sec 7a). For those having gained or commenced their overseas social work qualification after 2005, their qualification must either be equivalent to a Bachelor in Social Work or a postgraduate qualification in social work. For many migrants this has the potential to be an issue, if they currently domicile in a country where such qualifications are not required (Weiss-Gal \& Welbourne, 2008, p.286). Situations may result where a social worker with a number of years of professional experience overseas, but lacking the required comparable degree, or substantial social work experience in New Zealand might be considered ineligible to apply for registration.

Additionally, overseas-qualified social workers must demonstrate how their overseasattained social work qualification is equivalent to the Board's recognised qualifications for New Zealand-based practitioners, according to Section 7(a) of the Social Workers Registration Act, 2003. The exceptions to this are social workers who completed their social work qualification in England and are registered with the General Social Care Council in the United Kingdom, who are automatically deemed to have a qualification equivalent to a New Zealand social work qualification.

Finally, Section 7a of the Social Workers Registration Act, 2003 specifies that the SWRB must be satisfied that applicants who do not have a recognised New Zealand qualification are able to speak and write English reasonably effectively, and understand spoken and written English reasonably well. The Board's policy in turn, specifies that for applicants coming from countries where the medium of instruction in secondary and professional schooling is not English, applicants must sit the IELTS academic assessment and score at least a 'seven' in each of the four domains of English communication (SWRB, 2009). Both New Zealand and international research indicates that such assessments often present a formidable hurdle to skilled migrants in getting their qualifications deemed equivalent (Lillis et al., 2006).

Of those overseas-trained professionals who have gained New Zealand registration, the vast majority $(81.5 \%$ ) earned their qualifications in the country of their birth, as well as in English.

While globalisation has led to the increasing standardisation of content studied as part of a social work degree (Weiss-Gal \& Welbourne, 2008), and the placement of social work as a course of study in most countries' higher education systems, the nature of social work knowledge is based on its capacity to find local solutions to global problems (Simpson, 2009). Therefore in a cross-national survey of the programmes of study included in a social work qualification, a high degree of local knowledge teaching, specifically regarding working with vulnerable groups and particular developmental interventions meant to address the local social and economic context, continues to exist (Weiss-Gal \& Welbourne, 2008). This diversity is further compounded by differences across jurisdictions of the dominance of one or other educational / professional paradigm shaping social work education; for example, in some systems social work is predominantly informed by the social sciences, while in others it may be more informed by clinical psychology and health sciences.

The qualifications earned overseas by those registered with the SWRB vary significantly, depending on the part of the world in which each social worker gained their education and 
the educational and disciplinary pathway they took. A total of 50 different named qualifications appear in the list, with a further 31 majors or specialisations. ${ }^{1}$ Just on a quarter of the cohort (24.8\%) earned professional degrees at either undergraduate or postgraduate levels (BSW, BSW(Hons) or MSW), while others had undergraduate qualifications and diplomas in arts (BA) or science (BSc). Their majors were based in nearly as wide a range of disciplines, including psychology, public or social policy, social administration, social sciences, anthropology, as well as social work, welfare studies, community work and clinical practice. This variance illustrates the diversity of educational pathways that people may take into social work, and the large range of academic disciplines on which the profession draws.

Such a range of educational qualifications and disciplinary backgrounds may represent a strength of the profession globally, while also frustrating attempts by local agencies who recruit overseas-qualified social workers to provide comprehensive induction and orientation programmes to practitioners new to the New Zealand practice environment. This is because it may be impossible to assume a shared set of principles, approaches and values, as well as generally shared knowledge and skills. It would also be difficult for the professional association to advise local employers on how to anticipate induction needs of newly-recruited overseas staff, even if those social workers were able to be registered in New Zealand. This diversity of educational backgrounds may also highlight a more generalised challenge to this increasingly globalised profession of assuming - or establishing - a globally shared body of knowledge and skills.

In New Zealand, programmes of study focus on learning how to practise social work with those of Māori descent and other cross-cultural groups specific to the country, an area of local knowledge that is then expected to be demonstrated by those registering in the country (SWRB, 2009). It should be noted that Section 13b(i) of the Social Workers Registration Act empowers the SWRB to fully register an applicant without such a qualification when the Board is satisfied that his / her practical experience in social work is enough to compensate for such lack of a qualification. This clause requires the experience to be in New Zealand so cannot be utilised to grant registration to foreign social workers without the prerequisite qualifications, although the SWRB can consider other relevant qualifications and experience when people have spent extensive time in New Zealand before applying for registration. Migrant social workers registering under Section 7 of the Social Workers Registration Act must demonstrate through either the attestation of additional coursework, or documented evidence of a self-directed programme of learning how they have gained the necessary knowledge, skills and attitude to practise social work with Māori and with the diverse ethnic and cultural groups in New Zealand prior to attaining registration (SWRB, 2007a). The challenge for migrant social workers in 'proving' such competency is largely unknown and is a worthy topic of investigation as part of this study.

\section{Issues and challenges for migrant social workers}

Some of the challenges facing migrant social workers are the same as those confronting border-crossing professionals of all disciplines. These include difficulties in securing employment

While these majors are distinctly identified in the SWRB database, it must be recognised that many of the majors and specialisations listed may be more different in name only; there may well be substantial similarity and overlap in the content of these various credentials. 
commensurate with their qualifications and experience, due to perceived incomparability of qualifications (White, 2006), language and cultural barriers, unreasonable expectations or outright discrimination. Other challenges are more specific to the profession, such as the need to adjust to the nature of social work practice in a new historical, legal and political environment and a new legislative and policy context. The specific details of those challenges for New Zealand social work professionals trained elsewhere are being explored in this research project and reported in forthcoming publications. For the purposes of the present discussion, however, two issues present as being particularly timely for New Zealand practitioners and social service employers and managers, in light of the international literature. The issues addressed in the following discussion deal with the differences in professional and workplace cultures encountered by border-crossing social workers - and the ways in which professional acculturation may both complicate and contribute to a more general migrant acculturation experience - and the consequent need for more purposeful and responsive induction and on-going support of migrant social workers practising in New Zealand.

\section{Differences in the professional culture of social work across borders}

Social work, by nature of the profession, is one where professional culture does not translate easily across borders. While increasing globalisation of the profession has led to the professionalisation of social work as a practice, and the development of a set of Global Qualifying Standards (Beddoe \& Duke, 2009), evidence suggests that social work practice is still diverse and largely shaped by local context - in other words, the globalised values, ethical codes and standards are interpreted through the lens of national or regionally-specific historical, social, political and cultural norms (Welbourne et al., 2007; Simpson, 2009). The literature discusses this in a number of ways - from the scope of work and areas of practice that social workers engage in, to the relative status or role that social workers play or are afforded in society.

\section{Professional acculturation}

A number of recent researchers have suggested that the cultural specificity of practising social work makes the transferability of skills learned less straightforward than other skilled professions in a foreign context (White, 2006; Welbourne et al., 2007; Hussein, Manthorpe, \& Stevens, 2008; Crisp, 2009; Simpson, 2009). The practice of social work in a local context could involve dealing with individuals and groups whom the foreign-born and educated social worker may have no understanding of. Or, as Hussein et al. (2008, p.5) suggests, 'professional judgements, for example, over family assessment, seeking to understand both explicit and implicate clues, are culturally sensitive and sometimes specific.'

It is suggested in the literature that a critical component of cross-cultural practice for any migrant social worker is to become professionally acculturated, or communicatively and socially competent, in their newly adopted work situation (Hanks \& Sims, 2009). This may be particularly true in the New Zealand context, where increasing diversity amongst the population, and the bicultural foundations upon which the country is founded, make social work practice culturally specific. However, Nash and Trlin's (2004, p.34) research indicates that learning and demonstrating such competence - specifically knowledge about biculturalism and working with tangata whenua - is a continued challenge for some foreign-born social workers practicing in New Zealand.

It is very important, however, that employers and colleagues recognise that they can and will learn from the perspectives and experiences of migrant social workers. Professional 
acculturation in social work should involve a two-way exchange between the foreign social worker and local colleagues, where both come to understand the assets, strengths and opportunities that each group's background brings to professional practice (Brown et al., 2008). As migrant populations and cultural diversity increase within many countries, an international social worker may actually have a greater understanding of ways of approaching or working within this plurality. Yet a study of Australian-born and practicing social workers in Australia suggests that many social workers are yet to see the global dimensions of their local practices, and the possible lessons they can garner from their foreign-born colleagues (Findlay \& McCormack, 2005).

Whether migrant social workers in New Zealand see their 'outsider status' as an asset or a liability is unclear. The majority of those surveyed in Nash and Trlin's (2004, p.35) study believed that their ethnic background and/or language abilities were an advantage to them in their present position, particularly their empathy and understanding of feeling like an outsider in a new society. Yet few found their cultural knowledge and skills utilised effectively by their employers, according to the survey respondents. The current research project has also explored this dimension, via both survey and focus groups, and will address it in more detail in future publications.

\section{Professional roles and public recognition}

Weiss-Gal \& Welbourne (2008) explored at length differences in the professional features of social work in a comparative exercise involving 10 countries. One attribute that they found greatly varied was the status, public recognition and authority of the profession. Public recognition was measured in two ways. One was by whether there was any regulation over by whom and how the title of 'social worker' could be utilised amongst those practising within the profession. Several countries (India, Sweden, Hungary, and Mexico) either had no licensing requirements at all and/or did not restrict the use of the title 'social worker' to those who had specified qualifications. New Zealand restricts only the title 'registered social worker'. However, even in countries where such regulations do exist, it did not readily translate into public recognition of the profession. In many countries social work is still poorly understood amongst the public, with high degrees of ambivalence or negativity about the profession amongst many (Research Works 2001; Davidson \& King, 2005; Galilee, 2005).

Strong professional unions, and the social and political environment of the country also play a role in the status and purpose the profession is afforded in society. For example, in South Africa, where there are government-created systems to place social workers into an 'expert role', high degrees of professional autonomy were enjoyed by those in such positions (Weiss-Gal \& Welbourne, 2008, p.285). Similarly, social workers working in countries with strong support for the provision of social services or in countries with strong professional unions perceive a much higher status and professional role than they do in countries where this is not the case (White, 2006, p.636).

Low public recognition or status, or low degrees of professional autonomy do not always equate into poor remuneration compared to other caring professions. In the United Kingdom and South Africa, for example, the salaries social workers were paid were much higher than other countries, mainly due to the labour shortage facing the profession in these places (Weiss-Gal \& Welbourne, 2008, p.285). Yet, a common misconception, often held by social workers crossing borders, is that higher pay is equated with greater professional status 
afforded to the job. Many social workers who have migrated to the UK express disappointment when they realise that while they are getting paid more, their professional status is greatly diminished within social care (Hussein et al., 2008; Simpson, 2009).

For social workers crossing borders, the challenge occurs when initially adjusting to their new professional role and differing professional status. Many social workers migrating to the United Kingdom from countries where the role of social workers is not so tightly prescribed, or where there continues to be a greater role for such individuals in social policy formation, have found this transition to be difficult (White, 2006; Evans et al., 2007; Simpson, 2009). Likewise, for social workers accustomed to being held in high esteem within the community care environment and/or general society, working in a country where social work is poorly regarded - either by the public at large or by other professionals on multidisciplinary teams - or its role diminished is often a shock to such individuals (Jones, 2001; Hanks \& Sims, 2009).

\section{The importance of induction and ongoing support}

These differences have led to increasing recognition that upon arrival in a new country, social workers must be given support by their employers or recruiters to successfully bridge the professional divide. In particular recent comment has advocated induction programmes for such individuals, that:

- meet the needs of overseas workers in terms of necessary professional development;

- serve the needs of agencies and service users for whom these individuals will work for/with; and

- validate the prior experiences of these overseas workers and maintain or restore their professional competence (Hayes, 2004; Hussein et al., 2008; Simpson, 2009).

Employers are often constrained by a lack of time and appropriate resources to invest in such efforts, as well as the immediate need of filling critical gaps in service delivery to clients. Additionally, as demonstrated in the SWRB data above, professionals with social science qualifications may come with quite a different set of understandings and reference-points than those with science and clinical degrees, and might require quite different sorts of induction programmes. All these would be different again from those with professional social work qualifications, such as a BSW or MSW. An underlying assumption of many employers is that migrant social workers will 'adapt in time', yet the Social Care Association believes that more systemic support is necessary if the intent is to build a quality and long-term workforce. For the few employers who have offered such support, in the form of mentoring and cohort supports, research indicates that in the long-term, professional motivation has been maintained, and workforce attrition rates reduced (Simpson, 2009, pp.659-660).

\section{Post employment outcomes for migrant social workers}

For the foreign-born New Zealand social workers in Nash and Trlin's (2004) study, 68.7\% of them were highly satisfied with the job they were in. Not explored in their study were reasons for either being happy or not in their current employment. This area is of importance as the more general studies of skilled migrants working in New Zealand suggest that those working in the health care sector were more likely to report being either 'dissatisfied' or 'very dissatisfied' with their present employment, and more likely to be considering leaving their current employer (Wallis, 2006, pp.25-26). 
Where overseas practitioners are recruited because of shortages, it is often expected that these individuals will immediately relieve high case load volumes and work pressure. The reality can be the opposite, particularly in the absence of support for migrant social workers in the initial transitional period. Instead, short-term work pressures are likely to intensify as these new social workers accustom themselves to a new professional culture. For migrant social workers facing such pressure the long-term impact may be that they lose professional and personal competence, potentially impacting on their performance, motivation and commitment (Simpson, 2009).

While there are no definite studies in New Zealand or elsewhere on forms of discrimination against migrant social workers, studies from the health sector suggest that, while not always obvious, such conditions can impact on the confidence of migrants. In a study of the attitudes of overseas-trained nurses in the United Kingdom, discourse analysis of these individuals' narratives suggest that while denying the existence of discrimination in the workplace, the stories they shared uncovered covert forms of prejudice they were facing (Larsen, 2007). In particular many migrant nurses discussed persistent social undermining and questioning of their practices, as well as not being recognised for proven and demonstrated skills, as issues they faced in the workplace. However, rather than label it as discrimination, these nurses accepted such actions even though it had impacted on their professional motivation and workplace efficacy.

Whether workplace discrimination - though denied as actively occurring - may be covertly occurring and impacting on the sense of professional self-worth of migrant social workers has not been adequately explored in the research to date. Some research suggests that migrant social workers are perceived by co-workers and employers to be a 'second-best option', which could have consequences on the type of workplace environment experienced by these migrants (Simpson, 2009, p.663). In another qualitative study, one foreign-born social worker described how she felt 'ridiculed and criticised for accent' by both colleagues and service users (Hanks \& Sims, 2009, p.2). It remains to be seen whether such issues present themselves from the data collected as part of this study.

\section{Conclusion}

Walsh et al. (2010, p.1989) note that the paucity of research into social worker mobility leaves gaps, especially in terms of different experiences and pathways associated with migration - those through refugee and asylum-seeking pathways (resident and staying); those through spouse or familial employment (worker visas and possibly temporary); naturally occurring clusters of immigrants (employment-seeking immigrants); working global travellers (staying a year or two at most) - and whether the pathway adopted impacts on subsequent experiences and mobility. This article has highlighted knowledge about skilled migrants as it pertains to the social work workforce and offered an examination of key features of a cohort of currently registered overseas-trained social workers in New Zealand. It is clear that this group of professionals faces a range of issues and challenges with very significant implications for social work - and social work education - in New Zealand. The next phase of the project involves a larger study to address the knowledge gaps highlighted by Walsh et al. (2010), by exploring through focus groups and a survey the range of experiences and pathways of migrant social workers in New Zealand. As illustrated in the data presented, these border-crossers fill important vacancies in New Zealand's social care system, particularly 
in the statutory fields of health and child welfare. Building a greater understanding of their experiences, strengths and needs - as well as the challenges faced by those responsible for designing and implementing training and induction programmes for them - looks certain to be an increasingly pressing need amidst the growing globalisation of the professional social work workforce.

\section{References}

Bartley, A.J., Spoonley, P. (2008). Intergenerational transnationalism: The in-betweenness of 1.5 generation Asian migrants in New Zealand. International Migration, 46(4), 63-84.

Beddoe, L., \& Duke, J. (2009). Registration in New Zealand social work: the challenge of change. International Social Work, 52(6).

Brown, K., Bates, N., \& Keen, S. (2008). Supporting the recruitment of international social workers in the UK: A guide for employers. Birmingham: Learn to Care.

Christie, A., \& Campbell, J. (2009). Editorial: Special issue on crossing borders. Social Work Education: The International Journal, 28(6), 579-582.

Crisp, B. R. (2009). Is there a role for foreigners as social work educators? Social Work Education: The International Journal, 28(6), 668-677.

Cuban, S. (2008). Home/ work: The roles of education, literacy and learning in the networks and mobility of professional women migrant carers in Cumbria. Ethnography and Education, 3(1), 81-96.

Davidson, S. \& King, S. (2005). Public knowledge of and attitudes to social work in Scotland. Edinburgh: Scottish Executive Social Research. Retrieved 17 May 2010 from http://www.scotland.gov.uk/Publications / 2005/09/15142511/25120.

Department of Innovation, Industry, Science and Research. (2009). Trans-Tasman Mutual Recognition Arrangement. Retrieved 15 September 2010 from http: / / www.innovation.gov.au/Section/Industry/Pages/TransTasmanMutualRecognitionArrangement.aspx.

Department of Internal Affairs. (1996). High hopes: A survey of qualifications, training and employment issues for recent immigrants in New Zealand. Wellington: Department of Internal Affairs.

Evans, S., Baker, C., Huxley, P., White, J., \& Philpin, S. (2007). International recruitment of socail care workers and social workers in Wales - Final report. Swansea Centre for Social Carework Research, School of Human Sciences, Swansea University.

Experian. (2007). Overseas workers in the UK social care, children and young people sector. London: Skills for Care and Development.

Findlay, M., \& McCormack, J. (2005). Globalisation and social work: A snapshot of Australian practitioners' views. Australian Social Work, 58(3), 231-243.

Firth, R. (2004). Enabling social workers to work abroad. Paper presented at the IASW / IFSW Conference.

Galilee, J. (2005). Literature review on media representations of social work and social workers (21st Century Social Work, Social Work Scotland). Retrieved 17 May 2010, from http: / / www.socialworkscotland.org.uk/ resources / pub / SocialWorkersandtheMedia.pdf.

Hanks, S., \& Sims, D. (2009). Intercultural consolidation? Exploring the Experiences of internationally qualified social workers and the post qualifying framework. Paper presented at the 11th UK Joint Social Work Education Conference with the 3rd UK Social Work Research Conference (8-11th July 2009).

Hayes, D. (2004). Increase in overseas social workers poses ethical questions for councils. Community Care (1508), 18.

Hussein, S., Manthorpe, J., \& Stevens, M. (2008). People in places: A qualitative exploration of recruitment agencies' perspectives on the employment of international social workers in the United Kingdom. British Journal of Social Work, bcn131.

IMSED Research. (2009). Monthly migration trends. Wellington: Department of Labour.

Jones, C. (2001). Voices from the front line: State social workers and New Labour. British Journal of Social Work, 31(4), 547-562.

Larsen, J. A. (2007). Embodiment of discrimination and overseas nurses' career progression. Journal of Clinical Nursing, 16(12), 2187-2195.

Lillis, S., St George, I., \& Upsdell, R. (2006). Perceptions of migrant doctors joining the New Zealand medical workforce. New Zealand Medical Journal, 119(1229), 9p.

Lyns, K. (2006). Globalization and social work: International and local implications. British Journal of Social Work, 36(3), 365-380.

Masgoret, A., Merwood, P., \& Tausi, M. (2009). New faces, new futures: New Zealand. Wellington: Department of Labour.

Nash, M., \& Trlin, A. (2004). Social work with immigrants, refugees and asylum seekers in New Zealand. Palmerston North: New Settlers Programme, Massey University.

New Zealand Immigration Service. (2009). Skilled migrant category. Retrieved November 18, 2009, from http: / / www. immigration.govt.nz/migrant/stream/work/skilledmigrant/. 
New Zealand Immigration Service. (2010). Essential skills in demand lists. Retrieved 9 September, 2010, from http: / / www.immigration.govt.nz/migrant/stream/work/skilledmigrant/LinkAdministration/ToolboxLinks/essentialskills.htm?level $=1$.

North, N., Trlin, A., \& Singh, R. (1999). Characteristics and difficulties of unregistered immigrant doctors in New Zealand. New Zealand Population Review, 25(1/2), 133-143.

Penna, S., Paylor, I., \& Washington, J. (2000). Globalization, social exclusion and the possibilities for global social work and welfare. European Journal of Social Work, 3(2), 109-122.

Research Works (2001). Perceptions of social work and social care: Report of findings. Retrieved 17 May 2010 from: http: / / www.dh.gov.uk/en/Publicationsandstatistics/Publications/PublicationsPolicyAndGuidance/DH_4134351.

Simpson, G. (2009). Global and local issues in the training of overseas social workers. Social Work Education: The International Journal, 28(6), 655 - 667.

Smith, P. (2007). Editorial: Overseas-trained nurses, diversity and discrimination: Perceptions, practice and policy. Journal of Clinical Nursing, 16(12), 2185-2186.

Statistics New Zealand. (n.d.) Quick stats about culture and identity: 2006 Census. Retrieved from http:/ / www.stats. govt.nz / Census / 2006CensusHomePage / QuickStats / quickstats-about-a-subject/ culture-and-identity / birthplace-and-people-born-overseas.aspx.

SWRB. (2005). Code of Conduct for Social Workers. Wellington: Social Workers Registration Board / Kahui Whakamana Tauwhiro.

SWRB. (2007a). Policy statement on competence to practise social work with Maori and different ethnic and cultural groups. Wellington: Social Workers Registration Board.

SWRB. (2007b). Social Workers Registration Act (2003): Review Report. Wellington: Social Workers Registration Board/Kahui Whakamana Tauwhiro.

SWRB. (2009). Entitlement to Registration Policy Statement. Wellington: Social Workers Registration Board/Kahui Whakamana Tauwhiro.

van Lanen, M. (2008). Peeping at peers: a cross-national study of professionalism in social work. European Journal of Social Work, 11(4), 469-473.

Wallis, R. (2006). Skilled migrants in New Zealand: A study of settlement outcomes. Wellington: Department of Labour.

Walsh, T., Wilson, G., \& O'Connor, E. (2010). Local, European and global: An exploration of migration patterns of social workers into Ireland. British Journal of Social Work, 40(6), 1978-1995.

Weiss-Gal, I., \& Welbourne, P. (2008). The professionalisation of social work: A cross-national exploration. International Journal of Social Welfare, 17, 281-290.

Welbourne, P., Harrison, G., \& Ford, D. (2007). Social work in the UK and the global labour market: Recruitment, practice and ethical considerations. International Social Work, 50(1), 27-40.

White, R. (2006). Opportunities and challenges for social workers crossing borders. International Social Work, 49(5), 629-640. 